\title{
Milk Thistle Seed Extract Favorably Affects Lactation and Development of Mammary Gland in Female Rats
}

\author{
B. I. Mohammad ${ }^{*}$ H. A. Alzamely ${ }^{* *}$, F. K. Al Gharrawi ${ }^{* * * *}$ and H. A. Al-Aubaidy ${ }^{* * *}$ \\ ${ }^{*}$ College of Pharmacy, University of Al-Qadisiyah, Diwanyah, Iraq. \\ ** College of Veterinary Medicine, AL Qasim Green University, Babylon, Iraq. \\ *** School of Life Sciences, La Trobe University, 3086, Bundoora, Australia.
}

\begin{abstract}
$\mathbf{M}$ ILK thistle seed extract (Silbanummarianum), is a mixture of flavonolignans. The main active ingredients in S. marianum are silybin (silibinin), sylichrisitn, and silydianin, commonly referred to collectively as Sylimarin. Studies showed that Silymarin has antiinflammatory and antioxidant properties. Seventy-two pregnant female Wister rats were randomly assigned to 3 study groups (24 rats in each group). Group 1, or a control group (C group), received drinking water daily for 14 days from the 8 th day of gestation until the delivery. Group 2 (M) and Group 3 (S) received Metoclopramide (5mg $\backslash \mathrm{kg} \backslash$ day) and S. marianum seed extract (200 mg $\backslash \mathrm{kg} \backslash$ day), respectively, for 14 days. Dams' body weights were monitored throughout the pregnancy. The weights of the newborns in the litter (which previously adjusted to 8 offsprings) were measured on the first day of parturition, and 8 dams from each group were randomly selected and sacrificed. Pregnant female rats in (S) group had litter of significantly higher body weight and increase serum prolactin level in pregnant female rats $(\mathrm{p}<0.05)$. Milk thistle seed extract led to a marked hyperplasia in mammary gland tissue, with strong expression of prolactin receptors. Wister ratsinS. marianum and Metoclopramide groups showed significant increase in serum prolactin levels, had heavier offsprings, and histological and immunohistochemistry changes as compared to the animals that stopped receiving the treatment in the same group $(\mathrm{p}<0.05)$. We concluded that $\mathrm{S}$. marianum enhances milk production and mammary gland development (galactogogues effect).
\end{abstract}

Keywords: Silymarin, Mammary gland, Prolactin, Galactogogues, Milk production.

\section{Introduction}

Milk serves as an important economic resource. It is vital for animal growth and wellbeing as it is essential product during neonatal life and provides the essential immunoglobulins during early life period as well as later in life. Therefore, milk industries put more efforts toward establishing long term programs for development and care of livestock and conducting researches and scientific studies that would increase both quantity and quality of the milk [1].

The mammary glands are one of few organs in the body which are able to undergo repeated phases of growth, differentiation and regression. At the onset of puberty in the female, the increase in ovarian steroids induces elongation and sidebranching of the rudimentary mammary gland ductal system. Some differentiation of the ductal system occurs at this stage, resulting in a compact glandular structure. The gland, then remains relatively inactive until pregnancy [2].
A number of herbal plants, which contain large number of chemically active principles including alkaloids, having galactogenic properties, can be used as herbal medicine for the purpose of milk let-down in milking animals. Among these, Milk thistle (Silbanummarianum), Mother's milk tea, Ashwagandha and Shatavari plant ingredients have been emphasized in Ayurveda. Their inclusion in veterinary medicine as herbal galactogogues needs thorough and critical evaluation to identify their efficacy and if they possess some unwanted effects [3].

Milk thistle's (Silybummarianum) (S. marianum), is a given name acquired due to the white markings on the leaves, it's milky white sap, and its traditionally used by the nursing mothers to increase milk. But it has been previously known by its hepato-protective role and it can also act as a decongestant [4]. Silymarin is a unique flavonoid complex which is derived from the milk thistle plant. These unique phytochemicals have been the subject of decades of research into their 
beneficial properties [5].Therefore, the present study was designed to evaluate the in-vivo milk producing effects of Silymarin in pregnant and lactating female rats.

\section{Materials and Methods}

\section{Preparation of animals}

This study was approved by the Animal Ethics Committee, College of Veterinary Medicine, University of AL Qadisiyah, Iraq. Consider the actual numbers subjected to the study onlyatotal of one hundred and twenty mature Wister albino rats (80 females and 40 males)with a mean weight of $280 \pm 20 \mathrm{~g}$ was used in this study. All animals were kept in isolatedcagesand maintained on controlled conditions (temperature 20-25C $\mathrm{C}^{\circ}$, humidity $30-70 \%$ and alternating light and dark $12 \mathrm{~h}$ dark/light cycle). The animals had free access to regular chow diet consisting of $5 \%$ fat, $53 \%$ carbohydrate, $23 \%$ protein, with total calorific value $25 \mathrm{~kJ} / \mathrm{kg}$ and water ad libitum. After 2 weeks of acclimatization period, vaginal smear was made for 4 consecutive days and the rats that exhibited 2 consecutive estrus cycles were included in the study. Mating was performed by keeping the animals in a group caging system (two females and one male rat) for 3 days(vaginal smear samples were taken to confirm the presence of sperms in vagina which indicate the mating and considered as the $1^{\text {st }}$ day of pregnancy).

\section{Experimental design}

All the seventy-two pregnant female rats were randomly allocated into three study groups (24 rats in each group), making sure that each pregnant female was kept in a separate cage with litter enough for 8 offsprings:

- $\quad$ Control group $(\mathrm{C})$ received drinking water once daily from 8 th day of gestation till delivery.

- $\quad$ Metoclopramide group (M) received metoclopramide (5mg $\backslash \mathrm{kg} \backslash$ day) $[6,7]$ from 8th day of gestation till delivery.

- $\quad$ Silymarin group (S) received silymarin (200 mg $\backslash \mathrm{kg} \backslash$ day) [8-10] 8th day of gestation till delivery.

After parturition, litters' weights were adjusted to 8 pubs per dam (in the first day the $1^{\text {st }}$ day of parturition considered as $1^{\text {st }}$ day of lactation). Then eight Dams from each group have been sacrificed to obtain blood and tissue samples. The rest animals (16 dams per group) were further subdivide into two equal subgroups. In addition, the litters were allocated into the available dams (litter adjusted to 8 pubs per dam) $[8,9]$. The sub-groups are as follow: $(\mathrm{CB})$ received distilled water, $(\mathrm{CA})$ group received Silymarin (200mg $\backslash \mathrm{kg} \backslash$ day) [9], (MA) group continued with metoclopramide treatment $(5 \mathrm{mg} \backslash \mathrm{kg} \backslash$ day) $[6,7]$, (MB) group continue without metoclopramide treatment, (SA) group continued receiving Silymarin (200mg $\backslash \mathrm{kg} \backslash$ day) and (SB) group continued without Silymarin for 11 days from parturition (lactation period). At the $11^{\text {th }}$ day of lactation, the lactated dams were sacrificed to obtain the blood and tissue samples for further investigations.

\section{Drugs}

Metoclopramide is a dopamine receptor antagonist, which increases prolactin levels and causes mammary gland hyperplasia [6,7]. Oral drops were purchased from Julfar company, UAE and used at a dose of $(5 \mathrm{mg} / \mathrm{kg} /$ day $)$ [6,7]. Milk thistle seeds extract (Silymarin), oral drops were purchased from Natures Answer manufacturers for herbal extract, USA and used in a dose of (200mg $\backslash \mathrm{kg} /$ day) orally by stomach tube [8-10].

\section{Preparation of blood and tissue samples}

Four milliliters of blood samples were collected from the abdominal vein using disposable syringe under general anesthesia (Ketamine $90 \mathrm{mg} \backslash \mathrm{kg}$ and Xylazine $10 \mathrm{mg} \backslash \mathrm{kg}$, IP). One $\mathrm{ml}$ of serum was obtained and used for assessment of serum prolactin using ELISA technique. The mammary gland tissues were exteriorized and divided into two pieces and embedded separately in $10 \%$ formaldehyde solution. One part sent to histophysiological study and the other to immunohistochemistry analysis. All specimens were immediately placed in a fixative (10\% formaldehyde) solution for 24 hours, dehydration was achieved by ascending series of ethyl alcohols concentration.

\section{Assessment of study parameters}

Measurement of litters' body weight: This test was used to measure the changes in litters' body weight by using sensitive balance for all dams.Litters body weight was measured at first day of parturition and then daily until the $11^{\text {th }}$ day of lactation periodto record the changes in body weight in respect to diet and treatment type.

\section{Assessment of serum prolactin level}

According to the manufacturer instructions serum prolactin levels were assessed using ELISA kit (ABO Swiss Co., Ltd, China). 


\section{Histological and immunohistochemistry examination of mammary gland.}

Histological and morphometrical assessment of the mammary glands was performed to evaluate the structural changes of the glands, mammary gland sections were stained with haematoxylin and eosin. The numbers of (lobule, alveoli, acini per lobule, nuclei per one alveolus and diameter of alveoli) were performed using calibrated ocular micrometer and stage micrometer (LeitzWetzlar, Germany) [11]. Immuno - histochemistry examination was used to evaluate the expression of mammary gland prolactin receptors using the Allred scoring system. This system is evaluated by two categories (stain intensity (IS) and stain proportion (PS). The numerical value for overall intensity [intensity score (IS)] is based on a 4-point system: $0,1,2$, and 3 (for none, light, medium, or dark staining respectively). The numerical value for percent stained [proportion score (PS)] is determined by: no stain $=0(<10 \%), \leq 1 / 100$ cells stained $=1(10-25 \%), \leq 1 / 10$ cells stained $=2(25$ $50 \%), \leq 1 / 3$ cells stained $=3(50-75 \%), \leq 2 / 3$ cells stained $=4$, all cells stained $=5$. Addition of the two values gives the total Allred score (PS*IS), so the Allred score can vary between 0 and 8 (total $\mathrm{IS}=3$ and total $\mathrm{PS}=5$, so $3+5=8$ ) [10].

\section{Statistical analysis}

All the values were expressed as mean \pm standard error of the mean (SEM). Data of the experiment were analyzed using a split plot with the lactation treatment nested within gestation treatment, using F-test, regression analysis, and correlation coefficient. Least significant difference (LSD) was carried out to estimate the significance of difference between individual groups. P value less than 0.05 was considered significant.

\section{Results}

Litters'Body weight: Group S had a significant increase in litters' body weight as compared to other groups $(\mathrm{p}<0.05)$, (Fig. 1 A). Litters' weight of the Metoclopramide treated group was significantly higher than the control group $(\mathrm{p}<0.05)$, (Fig. 1 A).

At day $11^{\text {th }}$ of lactation, the cumulative litter weight gains were significantly high in Silymarin treated groups compared with that of control $(\mathrm{P}<0.05)$, (Fig. $1 \mathrm{C})$. In addition, lactating female rats that continued in receiving Silymarin and Metoclopramide registered significant increase in body weight as compared to the subgroups who stopped the treatment within the same group $(\mathrm{P}<0.05)$, (Fig.1 C). This significant difference was not seen between the control subgroups.

Serum prolactin levels: There were significant increase in serum prolactin levels in group $\mathrm{S}$ and group $\mathrm{M}$ as compared to group $\mathrm{C}$ in the first day after parturition, $(\mathrm{P}<0.05)$, (Fig.1 B).

On the other hand, serum prolactin levels were significantly elevated in subgroup SA as compared to SB. A similar trend was seen between subgroups MA and MB, ( $\mathrm{P}<0.05)$, (Fig.1 D). No such correlation was seen between subgroups $\mathrm{CA}$ and $\mathrm{CB}$.

Morphological alterations of mammary glands

Histological changes: The Silymarin group showed active secretory alveolar structures, with increased proportion of alveolar tissue and ductal system (hyperplasia), compared to the metoclopramide group and the control group (Fig.2 A).

In addition, this variation was very clear when comparing the relevant subgroups as shown in (Fig. 2 B \&C).

\section{Morphometric study}

Table 1 and 2 illustrate the numbers of (lobule, alveoli, acini per lobule, nuclei per one alveolus and diameter of alveoli), showing significantly increase in the overall of these parameters in the mammary gland of pregnant and lactated female rats which received Silymarin (group S, subgroup SA) as compared to the non-treated groups, (Table 1 and Table 2), $(\mathrm{P}<0.01)$.

\section{Immunohistochemistry study}

The mammary tissue of the silymarin treated group showed a strongly $(+++)$ positive expression of the prolactin receptors compared to metoclopramide group and the control group (Fig.3 A).

Moreover, during the lactation period, there is a strong expression ( +++$)$ of the PrlR in the silymarin continued treated subgroup (SA) as compared to the metoclopramide continued treated subgroup (MA) and the control group treated with silymarin subgroup (CA) (Fig. 3 B).

Non-significant differences in the levels of prolactin receptors (PrIP) were noticed in subgroups (SB, $\mathrm{MB}$ and $\mathrm{CB}$ subgroups, respectively), (Fig. $3 \mathrm{C}$ ). 
A

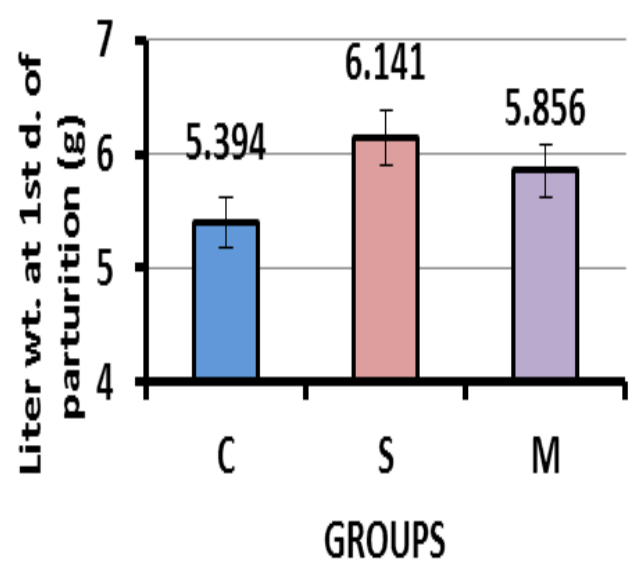

C

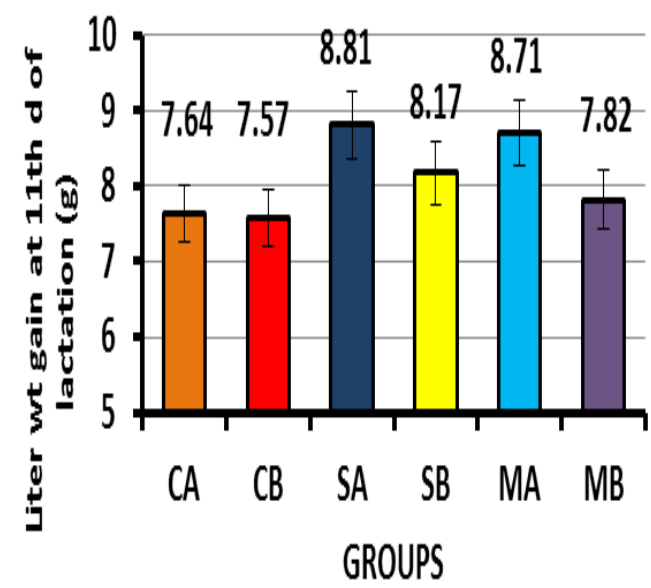

B

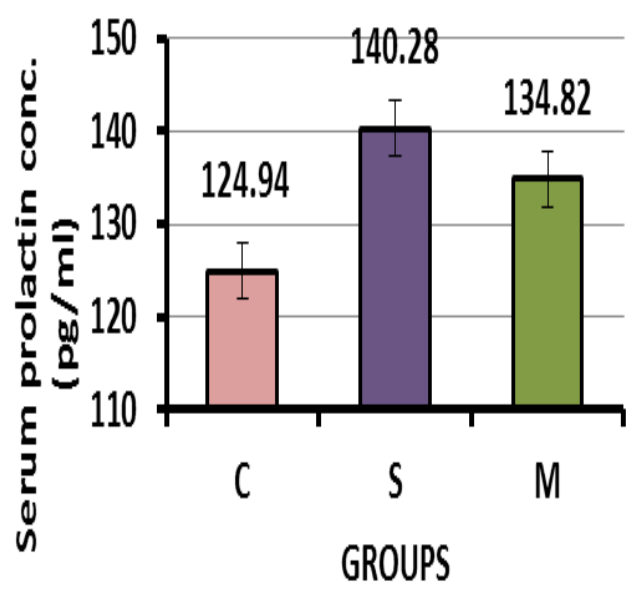

D

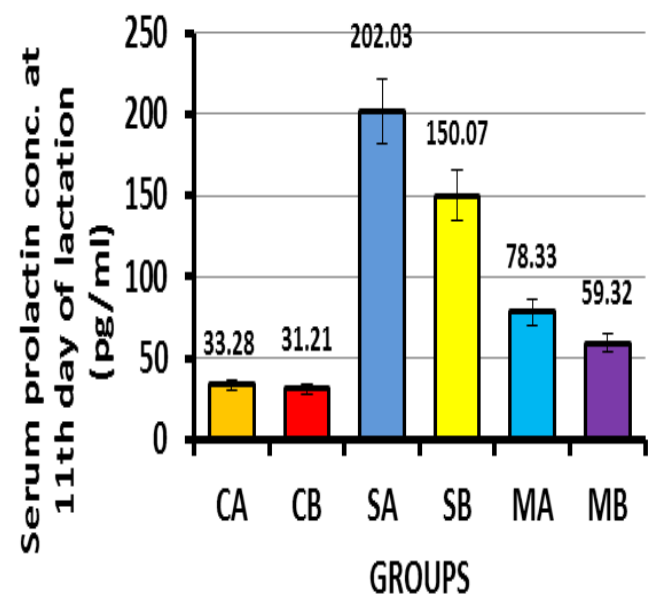

Fig. 1. The effects of oral administration of silymarin during 2 nd and 3rd stages of pregnancy in female rats on litter weight in grams (A) and serum prolactin concentration in $\mathrm{pg} / \mathrm{ml}$ (B) day 1 following parturition. The effects of oral administration of silymarin during $2 \mathrm{nd}$ and 3 rd stages of pregnancy in female rats on final litterweight gain in grams $(C)$, and serum prolactin concentration in $\mathrm{pg} / \mathrm{ml}$ (D) in day 11 of lactation.

Value expressed $\mathrm{M} \pm \mathrm{SE}$. Stars represent significant difference $(\mathrm{P}<0.05)$ as compared to the control.

$\mathrm{C}$ : litters of control rats received drinking water during $2^{\text {nd }}$ and $3^{\text {rd }}$ stages of pregnancy.

S: litter of rats received Silymarin $\left(200 \mathrm{mg} / \mathrm{kg}\right.$, bw) during $2^{\text {nd }}$ and $3^{\text {rd }}$ stages of pregnancy.

M: litter of rats received Metoclopramide $\left(5 \mathrm{mg} / \mathrm{kg}\right.$, bw) during $2^{\text {nd }}$ and $3^{\text {rd }}$ stages of pregnancy.

$\mathrm{CA}$ : control rats received silymarin from parturition to day $11^{\text {th }}$ of lactation.

$\mathrm{CB}$ : control rats received drinking water from parturition to day $11^{\text {th }}$ of lactation

MA: rats received metoclopramide from parturition to day $11^{\text {th }}$ of lactation.

MB: rats discontinued receive metoclopramide from parturition to day $11^{\text {th }}$ of lactation.

SA: rats received Silymarin from parturition to day $11^{\text {th }}$ of lactation.

SB: rats discontinued receive Silymarin from parturition to day $11^{\text {th }}$ of lactation. 


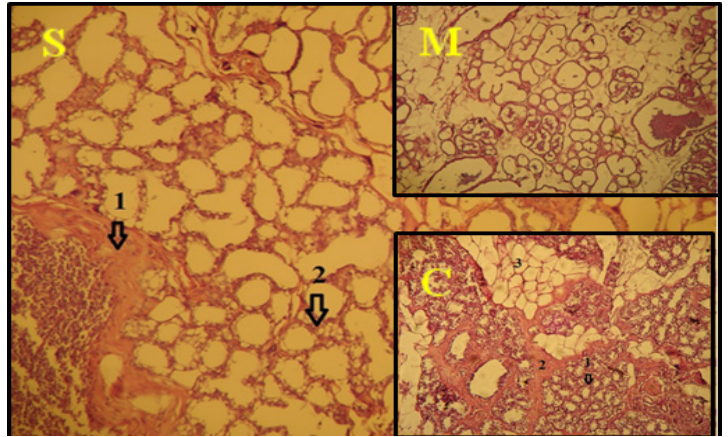

A

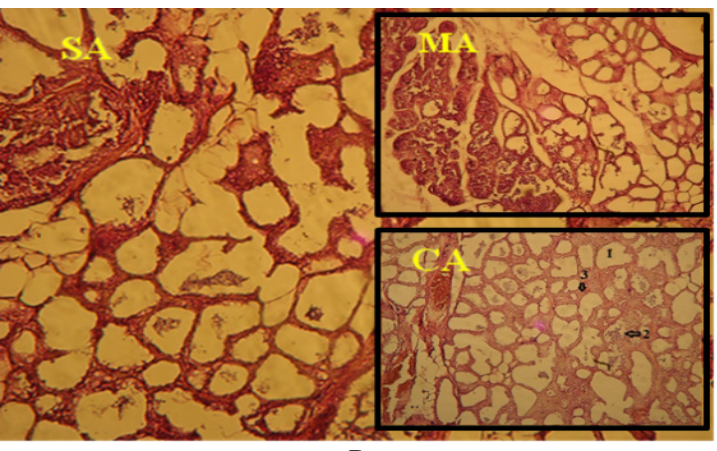

B

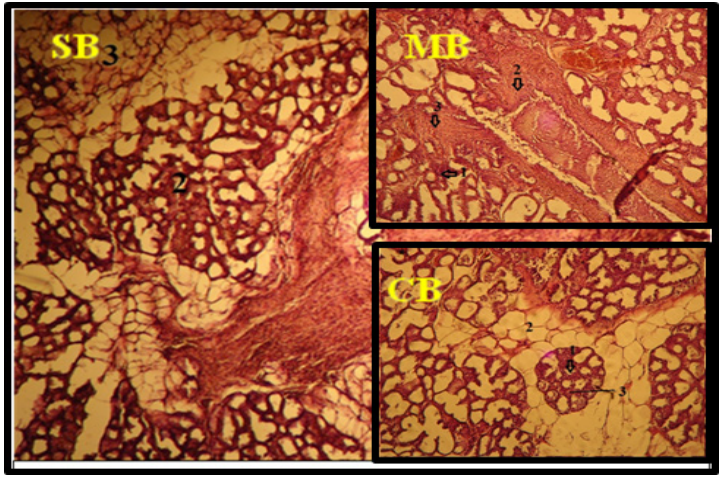

C

Fig. 2. A section of the mammary gland tissueingroups:stained with lectin stain and magnification using the Allred scoring system.

(S) showing 1 thin connective tissue, 2 active alveolar tissue (hyperplasia) fill with secretion (galactocele) which is characterized by vacuolated epithelial cells. The metoclopramide (M) group shows active ductal system filled with eosinophilic secretion (galactocele) with many elongated and bifurcated ducts, also the proportion of adipose tissue and connective tissue is markedly decreased. The control (C) group reveal 1 vacuolated acini surrounding by 2 thick connective tissue and 3 a proportion of adipose tissue.

A. (SA) showing active ductal alveolar system was the vacuolated cytoplasm of epithelial cells and increase in numbers with presence of secretion in the ducts. (MA) group characterized by active alveolar and ductal system, (1), the acini are fill with eosinophilic secretion (2) and (CA) group showed huge proportion of the stroma is occupied by well-developed lobules with many acini per lobule (1). The alveoli are filled with secretion (2). marked increase in the- size of lobules with little amount of adipose connective tissue (3) in between.

B. (SB) showing very thick connective tissue (1) with somewhat equally proportions of alveolar tissue (2) and adipose (3) and interlobular connective tissue. (MB) showed thick connective tissue (2), but dilated interlobular duct (1) and active alveoli and blood vessels also present, while the ductal system is stenosis (3). (CB) showed small glandular lobules (1) abundant of adipose tissue (2) and interlobular duct (3). H\&E 100X.

TABLE 1. Manifesting morphometry of some items in the mammary gland sections of pregnant female rat (using eye piece micrometer)

\begin{tabular}{ccccc}
\hline Group & No. of alveoli & No of acini/lobule & No. of lobule & $\begin{array}{c}\text { No. of nuclei } \backslash \\
\text { alveolus }\end{array}$ \\
\hline C & $6655.5 \pm 114.1$ & $22.66 \pm 0.89$ & $175.3 \pm 7.6$ & $5 \pm 0.14$ \\
M & $14117 \pm 117.06$ & $41.3 \pm 2.6$ & $237.5 \pm 165$ & $21 \pm 0.33$ \\
S & $17685 \pm 74.3^{*}$ & $43.75 \pm 1.04^{*}$ & $319 \pm 4.04^{*}$ & $28.5 \pm 0.23^{*}$ \\
\hline
\end{tabular}

Data are expressed as mean \pm SE

*Mention to the significances between groups $(\mathrm{P}<0.01)$. 
TABLE 2. Manifesting morphometry of some items in the mammary gland sections of lactated female rat (using eye piece micrometer)

\begin{tabular}{lccccc}
\hline Group & No. of alveoli & $\begin{array}{c}\text { No. of } \\
\text { acini/ lobule }\end{array}$ & No. of lobule & $\begin{array}{c}\text { No. of nuclei } \\
\text { alveolus }\end{array}$ & $\begin{array}{c}\text { Diameter of } \\
\text { alveoli } \backslash \boldsymbol{\mu m}\end{array}$ \\
\hline CA & $4759.6 \pm 119.6$ & $31.6 \pm 1.4$ & $166 \pm 11.3$ & $21 \pm 0.33$ & $78.6 \pm 1.47$ \\
CB & $4475.8 \pm 59.1$ & $26.3 \pm 1.6$ & $178.6 \pm 7.6$ & $5.5 \pm 0.23$ & $60.5 \pm 4.6$ \\
MA & $15606.6 \pm 141.8$ & $35.1 \pm 1.3$ & $330 \pm 5.25$ & $15.75 \pm 0.23$ & $78.8 \pm 1.39$ \\
MB & $8902 \pm 132.7$ & $41.3 \pm 1.25$ & $202 \pm 5.72$ & $9 \pm 0.14$ & $73.4 \pm 0.5$ \\
SA & $16514 \pm 83.08^{*}$ & $49.5 \pm 0.8^{*}$ & $256 \pm 5.27$ & $22.2 \pm 0.31$ & $104.7 \pm 1.94^{*}$ \\
SB & $9738 \pm 98$ & $33 \pm 1.2$ & $276 \pm 9.5$ & $5.8 \pm 0.2$ & $88.5 \pm 1.12$ \\
\hline
\end{tabular}

Data are expressed as mean \pm standard error

* Mention to the significances between groups $(\mathrm{P}<0.01)$.
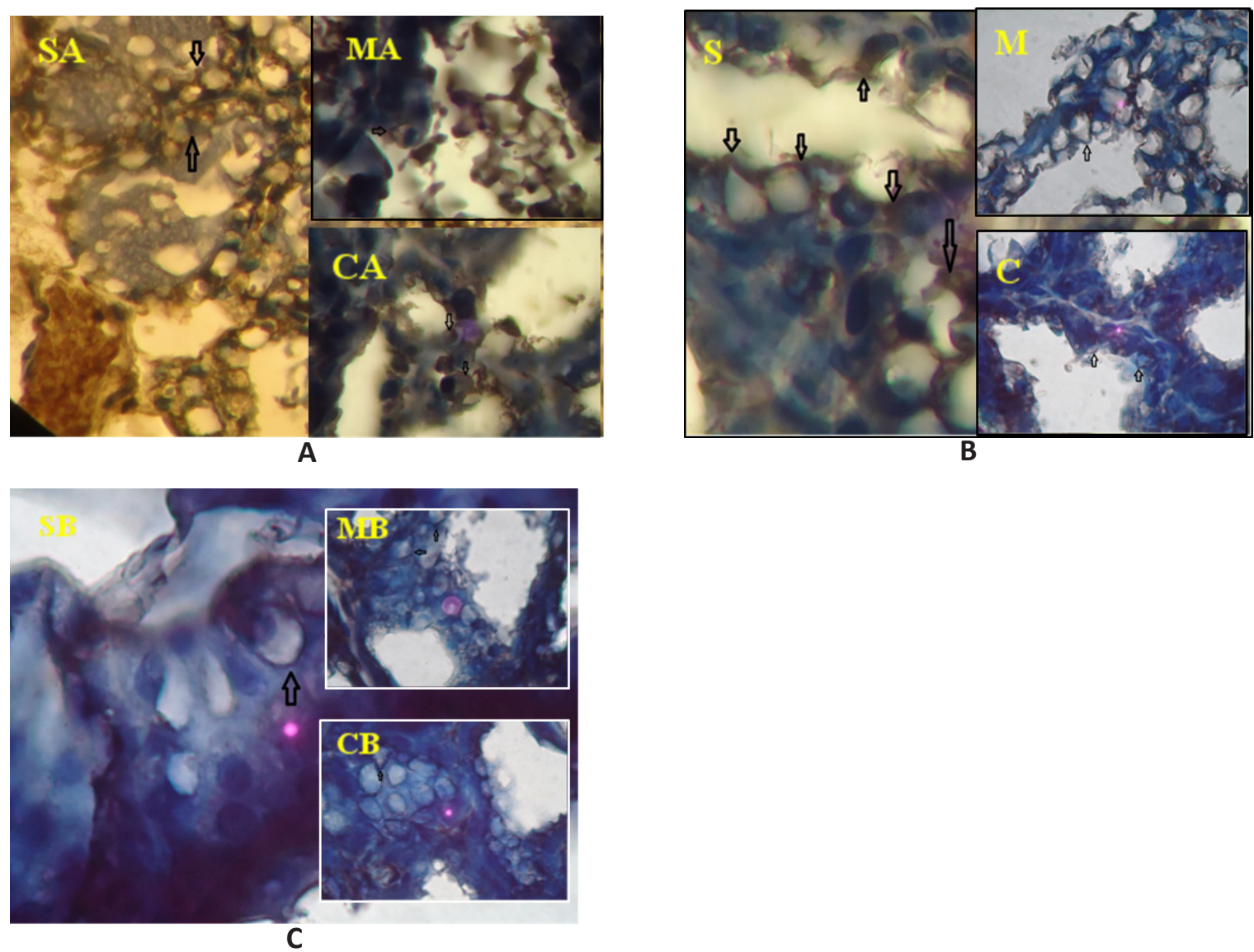

Fig. 3. sections of pregnant rat mammary gland tissue in groups: stained withhematoxylin and eosin and magnificationusing the Allred scoring system

A. (S) showed strong $(+++)$ expression of prolactin receptors. $(\mathrm{M})$ showed moderate $(++)$ expression of prolactin receptors. $(\mathrm{C})$ showed weak $(+)$ expression of prolactin receptors.

B. (SA) showed nearly strong $(+++)$ expression of prolactin receptors, positive staining. (MA) showed moderate $(++)$ expression of prolactin receptors. $(\mathrm{CA})$ showed weak $(+)$ expression of prolactin receptors.

C. (SB) showed weakly $(+)$ expression of prolactin receptors negative staining. $(\mathrm{MB})$ showed weakly $(+)$ expression of prolactin receptors negative staining. $(\mathrm{CB})$ showed weak $(+)$ expression of prolactin receptors negative staining. $\mathrm{IHC}, 1000 \mathrm{X}$ 
Qualitative analysis for immunohistochemistry indicated significantly increase $(\mathrm{P}<0.01)$ in mean of qualitative score (QS) $[\mathrm{Q}=\operatorname{Intensity}(\mathrm{I}) \times$ Proportion $(\mathrm{p})]$ of silymarin treated group $(\mathrm{S})(121.5 \pm 3.23)$ compared to the metoclopramide group (M) and control group (C) (47.5 $\pm 7.09,14.0 \pm 2.08)$ respectively, (Fig. 4 A).
Moreover, the (SA) group indicated a significant increase in the qualitative score compared to the (MA and CA) groups (Fig. 4 B). In addition, the (CA) subgroup has a significant increase in (QS) as compared to the non-treated subgroup (CB), (Fig. 4 B).

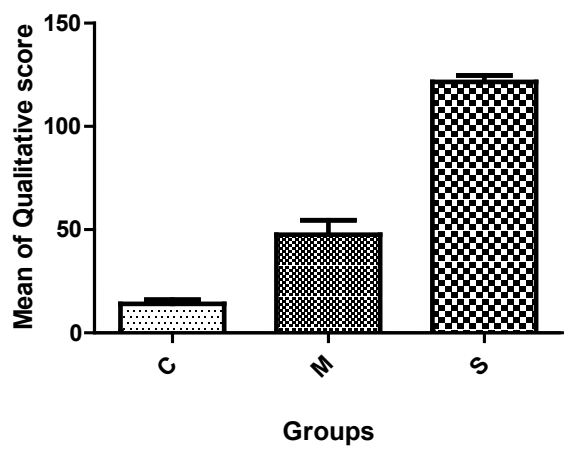

A
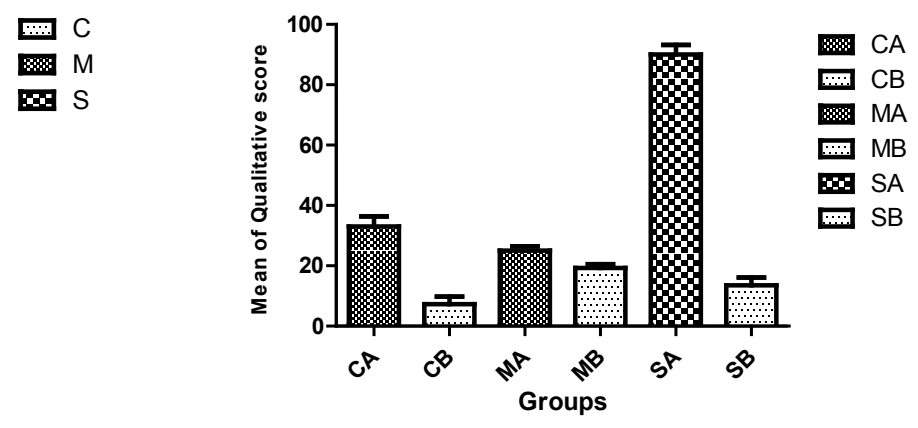

B

Fig. 4. Qualitative Analysis of mammary gland IHC during pregnancy (A) and during lactation (B).

C: litters of control rats received drinking water during $2^{\text {nd }}$ and $3^{\text {rd }}$ stages of pregnancy.

S: litter of rats received Silymarin $\left(200 \mathrm{mg} / \mathrm{kg}\right.$, bw) during $2^{\text {nd }}$ and $3^{\text {rd }}$ stages of pregnancy.

M: litter of rats received Metoclopramide $\left(5 \mathrm{mg} / \mathrm{kg}\right.$, bw) during $2^{\text {nd }}$ and $3^{\text {rd }}$ stages of pregnancy.

CA: control rats received silymarin from parturition to day $11^{\text {th }}$ of lactation.

$\mathrm{CB}$ : control rats received drinking water from parturition to day $11^{\text {th }}$ of lactation

MA: rats received metoclopramide from parturition to day $11^{\text {th }}$ of lactation.

MB: rats discontinued receive metoclopramide from parturition to day $11^{\text {th }}$ of lactation.

SA: rats received Silymarin from parturition to day $11^{\text {th }}$ of lactation.

SB: rats discontinued receive Silymarin from parturition to day $11^{\text {th }}$ of lactation.

\section{Discussion}

This study aims to evaluate the milk producing effects of silymarin in pregnant and lactating female rats. Our data showed that the silymarin increases the activity of mammary gland and thus milk production as evidenced by the increment in the litters' body weight.

There are several numbers of botanical remedies (e.g. anise, fennel fenugreek seed, nettle and milk thistle seed), which have been traditionally used to stimulate milk production[10, 11]. Some studies showed that an extract of milk thistle seed increase lactation in cows [12] and women [13]. This observation has gained a renewed interest in its galactogenic properties.
However, the mode of action of milk thistle is still unclear and require further studies [14]. In the present study we have demonstrated that silymarin increases serum prolactin levels in pregnant and lactated female rats at higher levels that the metoclopramide and control group. Moreover, female rats which continued on silymarin supplements from pregnancy to the $11^{\text {th }}$ day after parturition (lactation period), showed significant increase in serum prolactin levels compared to the silymarin discontinued subgroup after parturition [14]. These findings explain the positive effects of silymarin on serum prolactin during pregnancy and continued throughout the lactation. This fits with the mammogenesis processes (The major portion of mammary growth occurs during 
pregnancy and is controlled by hormones) [13]. The growth of the mammary glands is slow at the beginning of pregnancy, but the rate of growth accelerates as the pregnancy advances [15]. Mammogenesis during pregnancy has been shown to be exponential in cattle goats and guinea pigs [15]. Thus, prolactin and placental lactogen, which bind to prolactin receptor, act during three stages: lobulo budding during organogenesis, lobuloalevoler expansion during pregnancy, and lactational differentiation and maintenance milk secretion during lactation [16].

Prolactin hormone produced by the pituitary gland enhances two activities in the mammary glands such as stimulation of mammary gland growth during pregnancy and stimulation of milk production while nursing infant [17]. Therefore, drugs stimulating prolactin production are generally used to enhance milk production $[18,19]$. Our experiment has shown that silymarin, similarly to metoclopramide (drug have galactogenic properties), increase serum prolactin levels in female rats during pregnancy and lactation. This may be attributed to the antidopaminergic activity of silymarin[14] and the estrogenic effects of silymarin[20].Other studies declared that the estrogen is a positive regulator of prolactin production and release [21, 22]. In addition, estrogen decreases the expression of dopamine (DA-D2) receptors and number of $\mathrm{Gi} / \mathrm{o}$ immunoreactivelactotrophs that inhibit prolactin release [23]. These results could support the notion that the increment in milk production previously observed in cow and human $[12,13]$.

Studying the hormonal changes during pregnancy is a critical point to overview the rate of mammary gland growth and development during lactation. Since structural differentiation of the mammary gland, is in the direction of hormonal balances in adult mammals, major steps of this differentiation include, sequentially, formation of a lobulo-alveolar structure. Appearance of specific secretory activity, hypertrophy of epithelial cells of mammary gland characterized by an intense synthesis and secretion of milk, is related to such hormones responsible for these changes including estrogen, progesterone, prolactin, placental lactogen as well as other hormones related to the biochemical activity of mammary alveolar secretary cells [24].

In present study, the results of morphological alterations of mammary gland of pregnant female rats in the silymarin group revealed a marked ductal and lobulo-alveolar hyperplasia which are characterized by active secretory alveolar structures with increased proportion of alveolar tissue and ductal system in comparison with metoclopramide and control group. In addition, the female rats' subgroup (SA), which continued receiving silymarin, (from pregnancy to $11^{\text {th }}$ day of lactation), had a marked hyperplasia compared to the subgroup (SB) that discontinued silymarin. Also there is a moderate mammary gland hyperplasia in female rats which received silymarin after parturition for 11 days (lactation period). Morphologically, Silymarin increases in the number of (lobule, alveoli, acini per lobule, nuclei per one alveolus) and diameter of alveoli compared to controls and these findings may indicate that silymarin induces more proliferation and more differentiation in mammary glands of treated groups when compared with their nontreated controls [25].

The positive effect of silymarin on mammary gland growth and development in pregnancy period, might be explained by the anti-apoptotic activity of silymarin on mammary gland cells [25, 26]. In addition, we observed strongly expression of prolactin receptors (PrlR) in mammary gland of treated group compared to control group and Metoclopramide group. This observation may be attributed to estrogenic effect of Silymarin [20]. Estrogen is a positive regulator of prolactin production and release [22]. Kobayashi et al. (2013) declared that estrogen plays a pivotal role in the regulation of the gastro-hepato-pituitary axis [26], as well as of its own receptors.

In addition, the expression of PrlR was more significant in silymarin treated lactating female rats as compared to control group. This should fit with the findings from previous studies, who declared that rat mammary gland, PRLR expression is low during most of pregnancy, increases on day $21^{\text {st }}$ of pregnancy, likely in response to the antepartum rise of pituitary PRL release, and continues to increase throughout lactation. This demonstrates the positive role of silymarin on increase prolactin hormone in blood and in mammary gland.

\section{Conclusion}

It can be concluded that silymarin favorably affects milk production and enhances mammary gland development (galactogogues effect). Further studies should be directed toward detailed mRNA expressions levels of prolactin and prolactin receptor genes in pituitary and mammary glands 
of pregnant and lactating female rats.

\section{Conflict of interest}

Nothing to declare.

\section{List of Abbreviations}

Silybummarianum (S. marianum), Control group (C), Metoclopramide group (M), Silymarin group (S), Control subgroup received distilled water (CB), Control subgroup received Silymarin (200mg $\backslash \mathrm{kg} \backslash$ day) (CA), Metoclopramide subgroup continued with metoclopramide treatment $(5 \mathrm{mg} \backslash$ kglday) (MA), Metoclopramide subgroup continue without metoclopramide treatment (MB),Silymarin subgroup continued receiving Silymarin (200mg $\backslash k g \backslash$ day) (SA), Silymarin subgroup continued without Silymarin for 11 days from parturition (lactation period) (SB), one-way analysis of variance (ANOVA 1), Least significant difference (LSD).

\section{References}

1. Goff, H.D. and Griffiths, M.W., Major advances in fresh milk and milk products: fluid milk products and frozen desserts. J. Dairy. Sci., 89, 1163-1173 (2006).

2. Sternlicht, M.D., Key stages in mammary gland development: the cues that regulate ductal branching morphogenesis. Breast Cancer Res., 8, 201 (2006).

3. Mohanty, I., Senapati, M.R. and Jena, D., Ethnoveterinary importance of herbal galactogogues - a review. Veterinary World, 7, 325-330 (2014).

4. Wang, M., Xie, T. and Chang, Z., A New Type of Liquid Silymarin Proliposome Containing Bile Salts: Its Preparation and Improved Hepatoprotective Effects. PLoS One, 10, e0143625 (2015).

5. Lee, G. and Bae, H., Therapeutic Effects of Phytochemicals and Medicinal Herbs on Depression. BioMed Research International, doi: 10.1155/2017/6596241 (2017).

6. Fairweather-Tait, S.and Wright, A., Small intestinal transit time and iron absorption. Nutrition Research, 11, 1465-1468 (1991).

7. Jamali, F.and Axelson, L.E., Influence of metoclopramide and propantheline on GI absorption of griseofulvin in rats. J. Pharmac. Res., 66, 1540-1543 (1977).
8. Lynch, C.J. andAdams, S.H. Branched-chain amino acids in metabolic signalling and insulin resistance. Nature reviews Endocrinology, 10, 723-736 (2014).

9. DeSantiago, S., Torres, N.and Suryawan, A. et al., Regulation of branched-chain amino acid metabolism in the lactating rat. J. Nutr., 128, 1165 1171 (1998)

10. Capasso, R., Aviello, G.and Capasso, F., et al., Silymarin BIO-C, an extract from Silybum marianum fruits, induces hyperprolactinemia in intact female rats. Phytomedicine, 16, 839-844 (2009).

11. Allred, D.C., Harvey, J.M.and Berardo, M., Prognostic and predictive factors in breast cancer by immunohistochemical analysis. Mod. Pathol., 11, 155-168 (1998).

12. Tedesco, D., Domeneghini, C.and Sciannimanico, D. et al., Silymarin, a possible hepatoprotector in dairy cows: biochemical and histological observations. J. Vet. Med. A. Physiol. Pathol. Clin. Med., 51, 85-89 (2004).

13. Carotenuto, D.and Di Pierro, F., Studio sulla tollerabilita ed efficacia della silimarina BIOC micro-nizzata come galattagogo. Acta Neonantol. Pediatr., 4, 393-400 (2005).

14. Capasso, R., Effect of Silitidil, a standardized extract of milk thistle, on the serum prolactin levels in female rats. Nat. Prod. Commun., 9, 943-944 (2014).

15. Martinet, J., Head, H.and Houdebine, L., Biology of lactation, Mieux Comprendre, 1999.

16. Akers, R.M., A 100-Year Review: Mammary development and lactation. J Dairy Sci, 100, 10332-10352 (2017).

17. Ben-Jonathan, N., Hugo, E.R.and Brandebourg, T.D., Focus on prolactin as a metabolic hormone. Trends. Endocrinol. Metab., 17, 110-116 (2006).

18. Gabay, M.P., Galactogogues: medications that induce lactation. J. Hum. Lact., 18, 274-279 (2002)

19. Zuppa, A.A., Sindico, P.and Orchi, C. et al., Safety and efficacy of galactogogues: substances that induce, maintain and increase breast milk production. J. Pharm. Sci.,13, 162-174 (2010).

20. Demirci, B., Dost, T.and Gokalp, F., et al., Silymarin improves vascular function of aged ovariectomized rats. Phytother. Res., 28, 868-872 (2014). 
21. Pasolli, H.A., Torres, A.I.and Aoki, A., Influence of lactotroph cell density on prolactin secretion in rats. J. Endocrinol., 134, 241-246 (1992).

22. Le Tissier, P.R., Hodson, D.J.and Martin, A.O., Plasticity of the prolactin (PRL) axis: mechanisms underlying regulation of output in female mice Adv. Exp. Med. Biol., 846, 139-162 (2015).

23. Stojilkovic, S.S., Bjelobaba, I.and Zemkova, H., Ion Channels of Pituitary Gonadotrophs and Their Roles in Signaling and Secretion. Front Endocrinol. (Lausanne), 8, 126 (2017).

24. Li, G., Hayward, I.N.and Jenkins, B.R., Peptidylarginine Deiminase 3 (PAD3) Is Upregulated by Prolactin Stimulation of CID9 Cells and Expressed in the Lactating Mouse Mammary Gland. PLoS One, 11, e0147503 (2016).
25. Starvaggi Cucuzza, L., Motta, M.and Miretti, S. Positive effect of silymarin on cell growth and differentiation in bovine and murine mammary cells. J. Anim. Physiol. Anim. Nutr. (Berl), 94, 111117 (2010).

26. Kobayashi, H., Yoshida, S.and Sun, Y.J., Gastric estrogen increases pituitary estrogen receptor alpha and prolactin mRNAs during the different pathological conditions of the liver. Endocrine, $\mathbf{4 3}$, 170-183 (2013).

(Received 18/12/2018; accepted 12/03/2019)

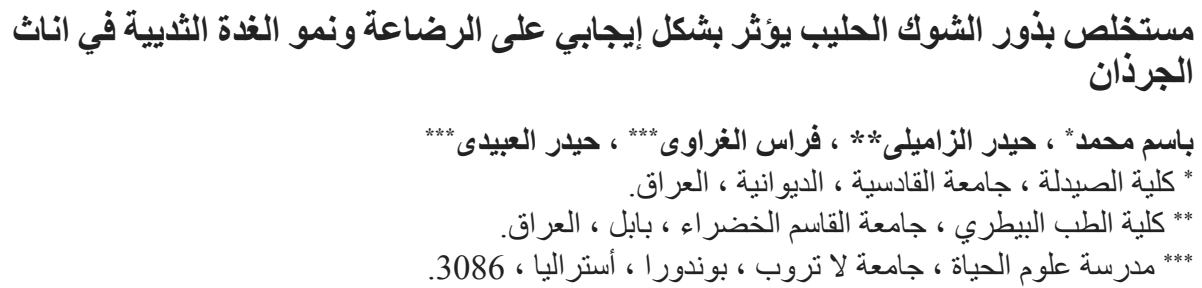

مستخلص بذور الثوك الحليب (Silbanummarianum) ، هو خليط من Sflavonolignans. المكونات

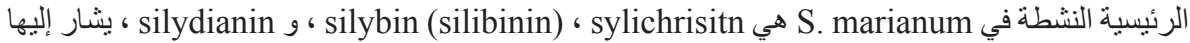

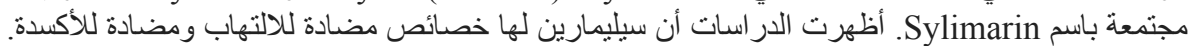

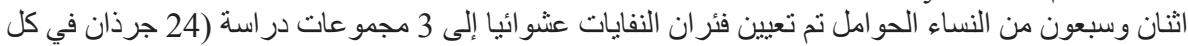

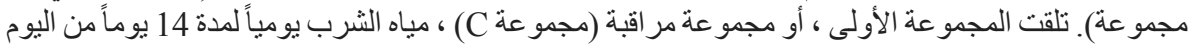

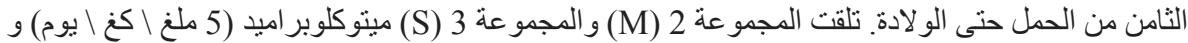

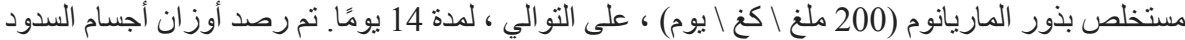

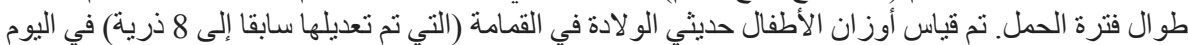

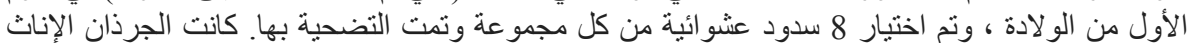

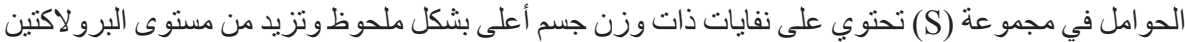

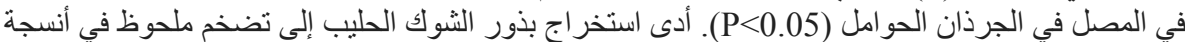

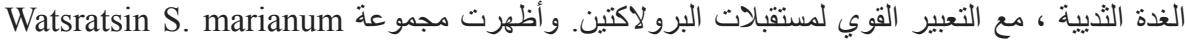

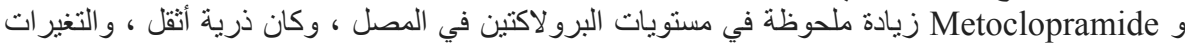

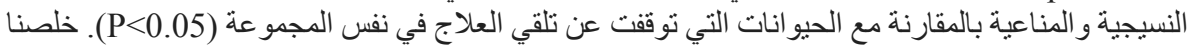

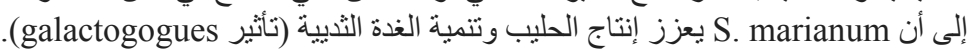

